\title{
TRANSPORT DISTRACTION OSTEOGENESIS FOR RECONSTRUCTION OF RAMUS-CONDYLE UNIT FOLLOWING RELEASE OF TEMPOROMANDIBULAR JOINT ANKYLOSIS
}

\author{
Moataz M.K Rizq ${ }^{1}{ }^{*} B D s$ Ahmed Mohamed Medra ${ }^{2} P h D$, Gamal El-Din Borhamy ${ }^{2} P h D$, \\ Mohamed Hussein Warda² $P h D$.
}

\begin{abstract}
INTRODUCTION: Temporomandibular joint (TMJ) is a structurally complex joint. TMJ deficiency and deformity can result from different causes. Ankylosis of the TMJ is considered the most common cause leading to severe form of deformity and shortening of the ramus / condyle unit which can affect both, function and esthetic and is difficult to treat. Different surgical procedures have been used to treat this deficiency, with variable degrees of success rates. Distraction osteogenesis is a well-established technique that is used to treat different maxillofacial deformities. A recent use in reconstruction of the deficiency ramus-condyle unit is developed

Aim: The objective of this study was to evaluate the use of transport distraction osteogenesis in restoring the deficient condyle/ramus unit of patients with unilateral or bilateral TMJ ankylosis to correct the resultant deformity.

MATERIALS AND METHODS: Ten patients with TMJ ankylosis underwent Transport condylar ramus distraction osteogenesis to reconstruct the condyle after release and gap arthroplasty. The distractors used were extraoral submerged ones. Patients were randomly allocated into two groups. The first group transport condylar distraction was done immediately in the same operation after release of ankylosis. In the second group, distraction was done in a second stage.

RESULTS: Our patients' age ranged from 2 to 46 years with an average of 18.2 years. The follow-up period ranged from 15 to 60 months with an average of 30.2 months. Successful treatment was achieved in seven cases. Complications were mild in two, moderate in four and severe in three. CONCLUSIONS: Transport condylar distraction osteogenesis is a valuable treatment option for TMJ ankylosis. It has a considerable complication rate that must be considered and discussed thoroughly with the patient/guardian. Also, improvement of the design and handling characteristics of the distractors must be considered.

KEYWORDS: Transport distraction osteogenesis, TMJ ankylosis, condyle, facial asymmetry, bird face deformity.

RUNNING TITLE: transport distraction osteogenesis for condylar reconstruction
\end{abstract}

(1) PhD student, Maxillofacial \& Plastic Surgery Department, Faculty of Dentistry, Alexandria University, Alexandria, Alexandria, EG

(2) Professor, Maxillofacial \& Plastic Surgery Department, Faculty of Dentistry, Alexandria University, Alexandria, Alexandria, EG

\footnotetext{
* Corresponding Author:

E-mail: mizox8@yahoo.com
}

\section{INTRODUCTION}

Temporomandibular joint (TMJ) is a structurally complex synovial joint that allows hinge and translation movements. (1) Deficiency in ramus and/or condyle can be congenital, traumatic or may result from surgical interventions to treat benign or malignant tumors. (2) Reconstruction of the ramus/condyle unit (RCU) is technically difficult and demanding. Several methods for TMJ reconstruction are being used with variable success rate such as gap arthroplasty, interpositional arthroplasty, the use of autogenous bone grafts and the use of alloplastic materials. Among the complications of these methods are; donor site morbidity, inconsistent pattern of growth of the graft especially the costochondral, and expenses of alloplastic materials. (3-5)
Recently, trials were done to reconstruct the RCU through the utilization of distraction osteogenesis principle. $(6,7)$ Experimental and clinical

studies proved the validity of this method. (8-13) The regenerated bone is similar in properties to the original one with no donor site morbidity. In this method a segment of bone is cut adjacent to the defect and moved gradually across the defect via a mechanical device. New bone is formed between the two segments. The segment of bone being moved is called transport disc. (14)

Distraction osteogenesis is the regeneration of bone between vascularized bone surfaces that are separated by gradual distraction. The bone is separated by low energy osteotomy or corticotomy stabilized by fixator (traction of callus). (15) 
Distraction osteogenesis was first reported by Codivilla in the early 20th century to lengthen the femur via application of external traction following an osteotomy. (16) Ilizarov, the Russian orthopedist performed several experimental and clinical studies that put the modern principles of distraction osteogenesis. (17-19)

McCarthy et al (20) were the first to perform successful clinical mandibular distraction. Since then, distraction osteogenesis has been used to treat wide varieties of craniomaxillofacial deformities. Advantages of this method are the elimination of donor site morbidity and the similarity of quality of the regenerated bone to the original bone $(10,21)$

Distractors used for mandibular distraction osteogenesis are either intraoral distractors placed in direct contact to the mandible or extraoral ones that are connected to the bone via external rods and pins $(2,6,13,21)$. The first successful clinical application for transport condylar distraction osteogenesis was performed by Stucki-McCormick in 1997.(22)

The aim of this study is to evaluate the use of transport distraction osteogenesis in restoring the deficient condyle/ramus unit of patients with TMJ ankylosis to correct the resultant deformity either unilaterally or bilaterally.

\section{MATERIALS AND METHODS}

The study was conducted on ten patients with jaw deformity, secondary to TMJ ankylosis, with deficiency in the ramuscondyle unit, who were admitted to the Maxillofacial and Plastic Surgery Department, Faculty of Dentistry, Alexandria University. The study was registered on the website www.ClinicalTrials.gov Identifier NCT04383964

Study design: Clinical trial

Inclusion criteria:

- Post ankylosis deformity: Bilateral or unilateral deficient ramus-condyle unit (RCU) after release. Bony ankylosed joints only were included. Patients were randomly allocated into two groups:

The first group: Patients in this group, underwent simultaneous release and distraction at the same operation.

The second group: Patients in this group, underwent release followed by distraction osteogenesis as a second stage.

Exclusion criteria:

- Mentally affected patients as well as those medically compromised were excluded from the current study.

Preoperative evaluation:

Patients were thoroughly evaluated after full history taking, comprehensive clinical examination and relevant laboratory and radiographic investigations (Panoramic radiographs, Posteroanterior cephalometric radiographs (PA ceph). Lateral cephalometric radiograph (lateral ceph) and Cone beam computerized tomography(CBCT). Photographs were obtained after obtaining patient's or guardian's consent. Ramus length was obtained from lateral cephalometric radiograph by measuring the distance between the g point, true vertical and true horizontal planes respectively( Preoperatively and postoperatively)

Distractors used were locally designed and made, unidirectional in vertical axis, with submerged distractors. In pediatric cases pediatric distractors were used, while in adult cases larger distractors were used.

\section{Operative Stage:}

The procedures were done under general naso-tracheal intubation, with the use of fiber optic intubation. Surgical procedures were done as follow

Release of bony ankylosis was performed through pre-auricular approach. A submandibular or retromandibular approach was used if ankylosis was already released. -A transport disc was created at the remaining stump of the Ramus-condyle unit (RCU) with an L shaped osteotomy. The prepared disc had to be wide enough to fit the upper portion of the distractor.

The submerged distractor was placed in a position to guide the transport disc moving up and backwards toward the glenoid fossa. The length of the distractor was determined according to the amount of distraction planned to reach the glenoid fossa. The distractor was applied and secured in place. The function of the distractor was checked then returned to zero position before closure. Finally, the wound was closed in layers and a drain was secured in place. Activation of the device was started after a latency period of five days, in a rate of $0.5 \mathrm{~mm}$ twice daily. Distractors were removed after a consolidation period of three months.

\section{Postoperative evaluation}

Included: mouth opening (measured with a ruler in millimeters), determination of the height of the ramus, and measurement of the airway on lateral cephalometric radiograph.

Results

Causes of ankylosis in our patients were post-traumatic in nine patients and a claimed congenital cause in one case (patient no. 4). Clinical features of the cases were as classically described in unilateral and bilateral TMJ ankylosis. Table 1 summarizes our patients' data

All patients were treated under general anesthesia for transport condylar distraction osteogenesis. They were divided into two groups:

The first group (group A):

Patients in this group, underwent simultaneous release and distraction at the same operation. This group included five patients: four males and one female. Table 2 summarizes the results of this group. The age of patients in this group ranged from 2 to 29 years with an average age of 12.8 years. The distraction period extended from 24 to 36 days, with an average of 29.2 days. The activation rate was 0.5 turn twice daily which is corresponding to $0.5 \mathrm{~mm}$ each half turn. The follow-up period ranged from 12 to 36 months with an average of 24.6 months. The mean preoperative ramus length was $97.4 \mathrm{~mm}$, while the mean postoperative ramus length was $106 \mathrm{~mm}$. The preoperative mean of upper pharyngeal airway was $7.2 \mathrm{~mm}$ and the lower pharyngeal airway was $5.4 \mathrm{~mm}$, while the mean postoperative upper pharyngeal airway was $8.4 \mathrm{~mm}$ and the mean postoperative lower pharyngeal airway was $6.8 \mathrm{~mm}$.

The mean postoperative mouth opening in this group was $21.2 \mathrm{~mm}$ with a range from 19 to $25 \mathrm{~mm}$.Complications in this group were classified into mild, moderate and severe. 
Table 1. Clinical Data of our patients

\begin{tabular}{|c|c|c|c|c|c|c|c|c|}
\hline $\begin{array}{c}\text { Case } \\
\text { no }\end{array}$ & Age & Sex & Site & Type of surgery & $\begin{array}{c}\text { Distraction } \\
\text { time }\end{array}$ & Follow-up & Complications & $\begin{array}{l}\text { Post-operative } \\
\text { mouth opening }\end{array}$ \\
\hline 1 & 29 & male & Rt. & Simultaneous Release \& Distraction & 28 days & 12 months & Anterior openbite & $26 \mathrm{~mm}$ \\
\hline 2 & 26 & Female & Biateral & Release Followed by Distraction & 19 days & 40 months & Reankylosis, anterior openbite & $24 \mathrm{~mm}$ \\
\hline 3 & 11 & Female & Lt. & Release Followed by Distraction & 17 days & 17 months & No Complications & $19 \mathrm{~mm}$ \\
\hline 4 & 29 & Female & Bilateral & Release Followed by Distraction & 43 days & 36 months & $\begin{array}{l}\text { marginal mandibular nerve injury, Bilateral temporal } \\
\text { nerve injury, hypertrophic scars }\end{array}$ & $20 \mathrm{~mm}$ \\
\hline 5 & 17 & Female & Lt. & Simultaneous Release \& Distraction & 32 days & 15 months & $\begin{array}{l}\text { mild postoperative infection, anterior openbite,hypertophic } \\
\text { scars }\end{array}$ & $21 \mathrm{~mm}$ \\
\hline 6 & 2 & male & Lt. & Simultaneous Release \& Distraction & 36 days & 36 months & marginal mandibular nerve injury & $23 \mathrm{~mm}$ \\
\hline 7 & 46 & Female & Rt. & Release Followed by Distraction & 20 days & 60 months & Relapse & $22 \mathrm{~mm}$ \\
\hline 8 & 6 & male & Rt. & Release Followed by Distraction & 19 days & 32 months & No Complications & $21 \mathrm{~mm}$ \\
\hline 9 & 11 & male & Rt. & Simultaneous Release \& Distraction & 26 days & 35 months & mild postoperative infection & $20 \mathrm{~mm}$ \\
\hline 10 & 5 & male & Rt. & Simultaneous Release \& Distraction & 24 days & 25 months & marginal mandibular nerve injury & $19 \mathrm{~mm}$ \\
\hline
\end{tabular}

Table (2): Clinical data of the first subgroup (simultaneous release \& distraction)

\begin{tabular}{|c|c|c|c|c|c|c|c|c|c|c|c|c|c|}
\hline \multirow{3}{*}{ Pt.no } & \multirow{3}{*}{ Age } & \multirow{3}{*}{ sex } & \multirow{3}{*}{ Site } & \multirow{3}{*}{$\begin{array}{c}\text { Distraction } \\
\text { time }\end{array}$} & \multicolumn{4}{|c|}{ Pharyngeal airway } & \multicolumn{2}{|c|}{ Ramus length } & \multirow{3}{*}{ Follow-up } & \multirow{3}{*}{ Post operative mouth opening } & \multirow{3}{*}{ Complications } \\
\hline & & & & & \multicolumn{2}{|c|}{ upper } & \multicolumn{2}{|c|}{ lower } & \multirow[t]{2}{*}{ pre } & \multirow[t]{2}{*}{ post } & & & \\
\hline & & & & & pre & post & pre & post & & & & & \\
\hline 1 & 29 & $\hat{0}$ & Rt. & 28 days & $6 \mathrm{~mm}$ & $7 \mathrm{~mm}$ & $6 \mathrm{~mm}$ & $8 \mathrm{~mm}$ & $95 \mathrm{~mm}$ & $103 \mathrm{~mm}$ & 12 months & $25 \mathrm{~mm}$ & Anterior openbite \\
\hline 5 & 17 & 우 & Lt. & 32 days & $8 \mathrm{~mm}$ & $9 \mathrm{~mm}$ & $4 \mathrm{~mm}$ & $6 \mathrm{~mm}$ & $105 \mathrm{~mm}$ & $120 \mathrm{~mm}$ & 15 months & $19 \mathrm{~mm}$ & $\begin{array}{l}\text { Mild postoperative infection. } \\
\text { Small anterior openbite } \\
\text { Hyprtrophic scars }\end{array}$ \\
\hline 6 & 2 & $\hat{o}$ & Lt. & 36 days & $5 \mathrm{~mm}$ & $7 \mathrm{~mm}$ & $4 \mathrm{~mm}$ & $5 \mathrm{~mm}$ & $99 \mathrm{~mm}$ & $101 \mathrm{~mm}$ & 36 months & $23 \mathrm{~mm}$ & Marginal mandibular nerve injury \\
\hline 9 & 11 & $\hat{0}$ & Rt. & 26 days & $8 \mathrm{~mm}$ & $9 \mathrm{~mm}$ & $6 \mathrm{~mm}$ & $7 \mathrm{~mm}$ & $102 \mathrm{~mm}$ & $112 \mathrm{~mm}$ & 35 months & $20 \mathrm{~mm}$ & Mild postoperative infection \\
\hline 10 & 5 & $\hat{\sigma}$ & Rt. & 24 days & $9 \mathrm{~mm}$ & $10 \mathrm{~mm}$ & $7 \mathrm{~mm}$ & $8 \mathrm{~mm}$ & $86 \mathrm{~mm}$ & $\begin{array}{c}98 \\
\mathrm{~mm} \\
\end{array}$ & 25 months & $19 \mathrm{~mm}$ & Marginal mandibular nerve injury \\
\hline
\end{tabular}

Table (3): Clinical data of the second subgroup (release followed by distraction)

\begin{tabular}{|c|c|c|c|c|c|c|c|c|c|c|c|c|c|}
\hline \multirow{3}{*}{ Pt.no } & \multirow{3}{*}{ Age } & \multirow{3}{*}{ sex } & \multirow{3}{*}{ site } & \multirow{3}{*}{$\begin{array}{c}\text { Distraction } \\
\text { Time }\end{array}$} & \multicolumn{4}{|c|}{ Pharyngeal airway } & \multicolumn{2}{|c|}{ Ramus length } & \multirow{3}{*}{ Follow-up } & \multirow{3}{*}{$\begin{array}{l}\text { Postoperative } \\
\text { Mouth opening }\end{array}$} & \multirow{3}{*}{ Complications } \\
\hline & & & & & \multicolumn{2}{|c|}{ Upper } & \multicolumn{2}{|c|}{ Lower } & \multirow{2}{*}{ Pre } & \multirow[t]{2}{*}{ post } & & & \\
\hline & & & & & Pre & Post & Pre & Post & & & & & \\
\hline 2 & 26 & q & Bilateral & 19 days & $8 \mathrm{~mm}$ & $8 \mathrm{~mm}$ & $4 \mathrm{~mm}$ & $5 \mathrm{~mm}$ & 97 & 103 & 40 months & $24 \mathrm{~mm}$ & $\begin{array}{c}\text { Reankylosis, } \\
\text { Anterior openbite }\end{array}$ \\
\hline 3 & 11 & 운 & Lt. & 17 days & $9 \mathrm{~mm}$ & $10 \mathrm{~mm}$ & $5 \mathrm{~mm}$ & $8 \mathrm{~mm}$ & 91 & 100 & 17 months & $19 \mathrm{~mm}$ & No complications \\
\hline 4 & 29 & o & Bilateral. & 43 days & $6 \mathrm{~mm}$ & $8 \mathrm{~mm}$ & $4 \mathrm{~mm}$ & $6 \mathrm{~mm}$ & 98 & 109 & 36 months & $20 \mathrm{~mm}$ & $\begin{array}{l}\text { Marginal mandibular nerve } \\
\text { injury, Bilateral temporal nerve } \\
\text { injury, hypertrophic scars }\end{array}$ \\
\hline 7 & 46 & 오 & Rt. & 20 days & $9 \mathrm{~mm}$ & $11 \mathrm{~mm}$ & $7 \mathrm{~mm}$ & $9 \mathrm{~mm}$ & 101 & 113 & 60 months & $22 \mathrm{~mm}$ & Relapse \\
\hline 8 & 6 & $\widehat{\partial}$ & Rt. & 19 days & $6 \mathrm{~mm}$ & $9 \mathrm{~mm}$ & $6 \mathrm{~mm}$ & $7 \mathrm{~mm}$ & 89 & 101 & 32 months & $21 \mathrm{~mm}$ & No complications \\
\hline
\end{tabular}

Mild complications occurred in two patients (patients 5 and 9) in the form of postoperative infection that was controlled with antibiotics and resolved completely after device removal.

Moderate complications occurred in three patients (patients 5, 6 and 10) in the form of small anterior open-bite and hypertrophic scars in patient no. 5 and marginal mandibular nerve injury with mild residual defect in patients no. 6 and 10 .

Severe postoperative complication occurred in one patient (patient no. 1) in the form of development of severe anterior open-bite.

The second group (group B):

Patients in this group, underwent release followed by distraction osteogenesis as a second stage. This group included five patients: four females and one male. Table 3 summarizes the results of this group.

The age of patients in this group ranged from 6 to 46 years with an average age of 23.6 years. The distraction period extended from 19 to 43days, with an average of 23.6 days. The activation rate was 0.5 turn twice daily which is corresponding to $0.5 \mathrm{~mm}$ each half turn. The follow-up period ranged from 17 to 60 months with an average of 37 months. The mean preoperative ramus length was $97.4 \mathrm{~mm}$, while the mean postoperative ramus length was $105.2 \mathrm{~mm}$. The preoperative mean of upper pharyngeal airway was $7.6 \mathrm{~mm}$ and the mean preoperative lower pharyngeal airway was $5.2 \mathrm{~mm}$. The postoperative mean of upper pharyngeal airway was $9.2 \mathrm{~mm}$ and the mean postoperative lower airway was $7 \mathrm{~mm}$. Postoperative mouth opening ranged from 19 to $24 \mathrm{~mm}$ with a mean of $21.2 \mathrm{~mm}$.

Complications were classified into mild, moderate and severe. No complications occurred in two patients.

Moderate complications occurred in one patient (patient no. 4) in the form of marginal mandibular nerve injury with mild 
residual defect, bilateral temporal nerve injury and hypertrophic scars.

Severe postoperative complication occurred in two patients (patients no. 2 and 7) in the form of re-ankylosis with development of anterior open-bite in patient no. 2 and relapse in patient no 7 .
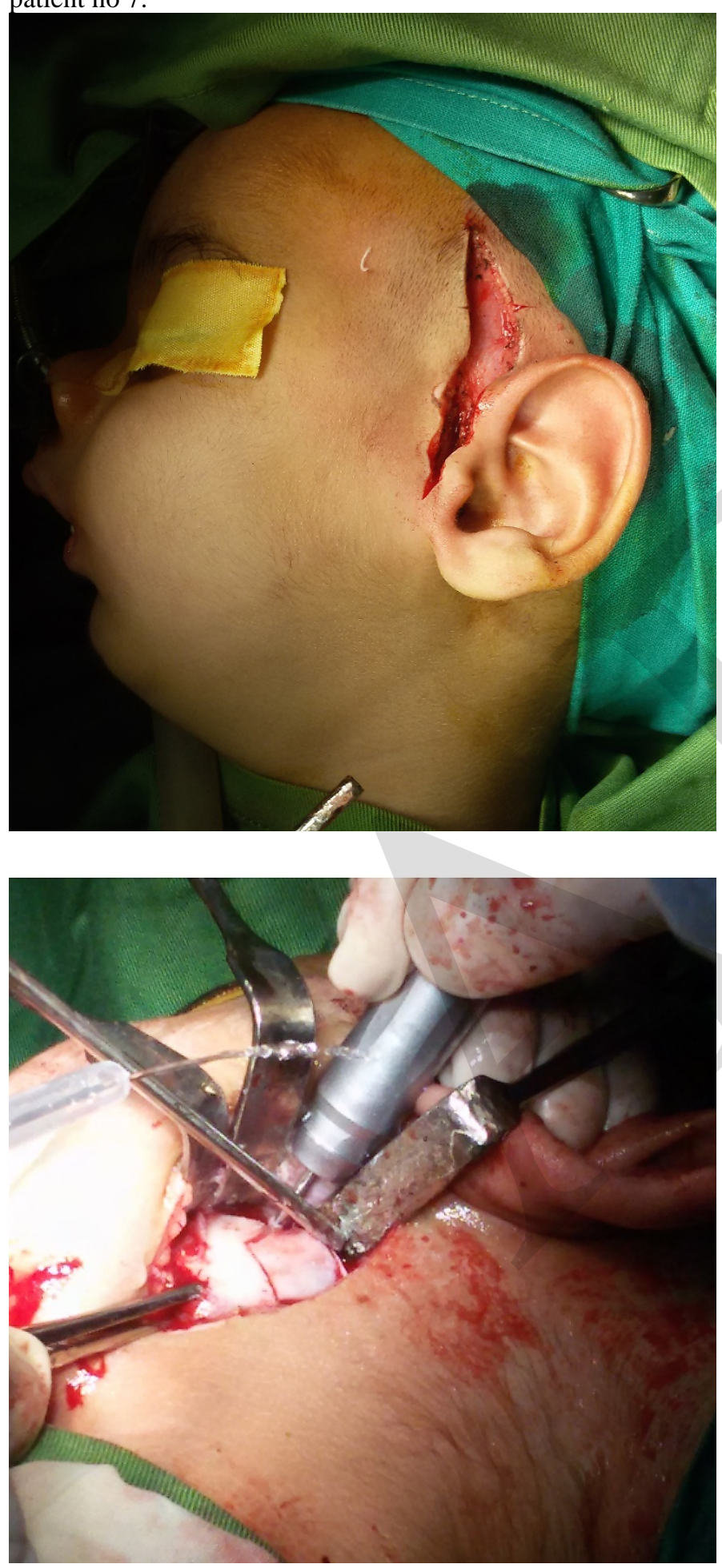

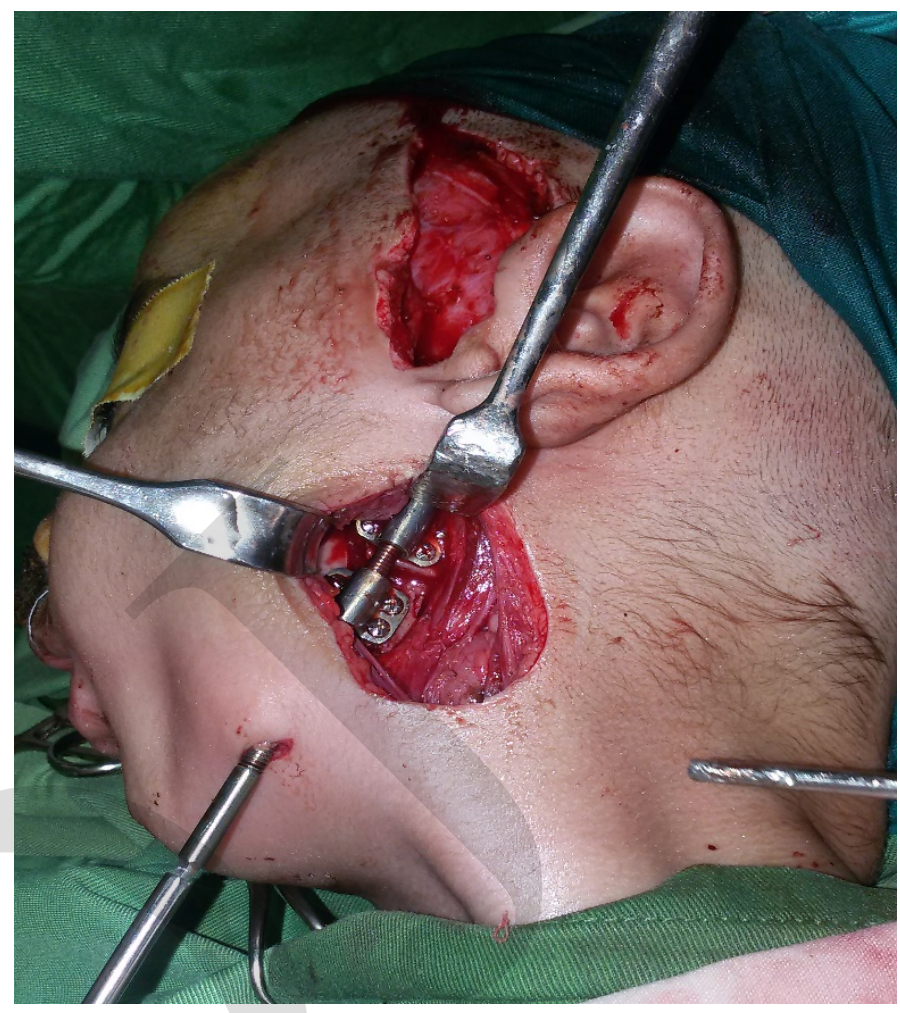

\section{DISCUSSION}

TMJ ankylosis is a condition that can produce severe disability to the affected person. When occurring in childhood it will interfere with facial development and will lead to face and jaws deformity with inability to perform adequate function and even will distort the patient's social relationships. (23) The earlier the ankylosis occurs, the more severe is the resulting deformity (24, 25).Trauma is the commonest etiological factor leading to ankylosis of the temporomandibular joint representing more than $98 \%$ of the cases. (26)

Our series consisted of eight unilateral cases and two bilateral cases treated with transport condylar distraction osteogenesis via submerged distractors.

Due to its simplicity, ease of execution and time conservation, the utilization of gap arthroplasty alone followed by aggressive physiotherapy for treatment of TMJ ankylosis is advocated by some surgeons mentioning that the recurrence rate can be as low as $2 \%$ or even $0 \%$. $(27,28)$ Other operators obtained higher unacceptable recurrence rate that is decreased by the use of inter-positioning graft with an increased maximal inter-incisal opening (MIO). (29, 30) The use of costochondral graft for reconstruction of the ramus condyle unit had been done successfully for a long time. The advantages of costochondral grafting include the biological and anatomical similarities to the condyle, low morbidity and regeneration of donor sites, restoration of the masticatory function, and a demonstrated growth potential in juveniles, while the disadvantages include pain, infection and the uncontrolled and unpredictable growth and the need for a second surgical site $(3,4,26)$

The Advantages of distraction osteogenesis includes the following: $(31,32)$ elimination of the need for bone grafting and donor site morbidity, augmentation of hard and soft tissue 
structures, increased stability when used for certain indications, decrease in neurosensory impairment, decreased blood loss, decreased operative time, and shorter hospital stay.

The devices used for distraction in our series were semi-buried ones that were inserted and removed via extraoral approaches but have no external rods passing through the skin. The only part that protruded from the skin was the activating rod. These devices share the advantages of intraoral distractors such as:(12, $33,34)$ causing less discomfort to patients, being hidden with only the activating rod protruding through the skin, not hindering the patients' activities which improves the quality of life, avoidance of pin related infections and scarring and being more convenient during intraoperative insertion and fixation in place.

Disadvantages of semi-buried distractors are generally the same as the intraoral ones: being monodirectional with inability to change the vector of distraction and that their removal requires complicated procedures under general anesthesia.

The success of the concept of distraction osteogenesis, lead to the development of transport distraction osteogenesis in which a bony disc is created following osteotomy. The transport disc is gradually moved away toward the defect and bone is created into the defect $(7,11)$ Reconstruction of the ramus condyle unit had been one of the applications of transport condylar distraction osteogenesis since the first successful case done by Stucki-McCormick. (22, 35, 36) Xiao et al (36) concluded that transport distraction osteogenesis could be considered successful in restoration of the mouth opening, however, the height of the reconstructed condyle was lacking stability. We agree with Verlinden et al (37) that transport distraction osteogenesis is generally successful but there is considerable complication rate that must be discussed with the patient preoperatively and the treatment plan should be tailored on individual bases. In conclusion, we think that more effort can be directed toward improvement of the design and the handling characteristics of the distractors.

\section{REFERENCES}

1. Standring S. Gray's anatomy : the anatomical basis of clinical practice. 41st ed: Elsevier; 2016.

2. Lars Andersson K-EK, M. Anthony Pogrel. Oral and Maxillofacial Surgery. 1st ed. Chichester, West Sussex, UK: Wiley-Blackwell; 2010.

3. El-Sheikh MM, Zeitoun IM, Medra AM. The split rib bundle graft in mandibular reconstruction. Journal of CranioMaxillofac Surg. 1992; 20 :326-32.

4. Medra AMM. Follow up of mandibular costochondral grafts after release of ankylosis of the temporomandibular joints. Br J OralMaxillofac Surg. 2005; 43: 118-22.

5. Neelakandan RS, Raja AVDK, Krishnan AM. Total Alloplastic Temporomandibular Joint Reconstruction for Management of TMJ Ankylosis. J Maxillofac Oral Surg. 2014; 13: 575-82.

6. Mehrotra D, Chellappa AAL, Gupta C, Passi D, Kumar S. Reconstruction of ramus-condyle unit with transport distraction osteogenesis: Report of eight cases and review of literature. J Oral Biol Craniofac Res. 2012; 2: 144-8.
7. Bansal V, Singh S, Garg N, Dubey P. Transport distraction osteogenesis as a method of reconstruction of the temporomandibular joint following gap arthroplasty for post-traumatic ankylosis in children: a clinical and radiological prospective assessment of outcome. Int J Oral Maxillofac Surg. 2014; 43: 227-36.

8. Li J, Ying B, Hu J, Zhu S, Braun TW. Reconstruction of mandibular symphyseal defects by trifocal distraction osteogenesis: an experimental study in Rhesus. Int J Oral and Maxillofac Surg. 2006; 35 : 159-64.

9. Zhu S-S, Hu J, Ying B-B, Li J-H. Growth of the Mandible after Condylar Reconstruction Using Transport Distraction Osteogenesis: An Experimental Investigation in Goats. Plast Reconstr Surg. 2008;121: 1760-7.

10.Zheng LW, Ma L, Shi XJ, Zwahlen RA, Cheung LK. Comparison of Distraction Osteogenesis Versus Costochondral Graft in Reconstruction of Temporomandibular Joint Condylectomy With Disc Preservation. J Oral Maxillofac Surg. 2011; 69: 409-17.

11. Kuriakose MA, Shnayder Y, DeLacure MD. Reconstruction of segmental mandibular defects by distraction osteogenesis for mandibular reconstruction. Head \& Neck. 2003; 25: 816-24.

12. Wang Jj, Chen J, Ping Fy, Yan Fg. Double-step transport distraction osteogenesis in the reconstruction of unilateral large mandibular defects after tumour resection using internal distraction devices. Int J Oral Maxillofac Surg. 2012; 41: 587-95.

13.Zwetyenga N, Siberchicot F, Emparanza A. Reconstruction of large mandibular and surrounding soft-tissue defects using distraction with bone transport. Int $\mathrm{J}$ Oral and Maxillofac Surg. 2012;41: 1215-22.

14. Sacco AG, Chepeha DB. Current status of transport-discdistraction osteogenesis for mandibular reconstruction. The Lancet Oncol. 2007; 8: 323-30.

15. Aronson J. Prinicples of distraction osteogenesis: The orthopedic experience. In: Distraction of the craniofacial skeleton. McCarthy JG (editor) 1st ed. Springer New York. USA 1999

16. Codivilla A. The classic: On the means of lengthening, in the lower limbs, the muscles and tissues which are shortened through deformity. 1905. Clin Orthop Relat Res. 2008; 466 : 2903-9.

17. Ilizarov GA. The Tension-Stress Effect on the Genesis and Growth of Tissues: Part I. The Influence of Stability of Fixation and Soft-Tissue Preservation. Clin Orthop Relat Res. 1989; 238: 249-81

18. Ilizarov GA. The Tension-Stress Effect on the Genesis and Growth of Tissues: Part II. The Influence of the Rate and Frequency of Distraction. Clin Orthop Relat Res. 1989; 239: 263-85.

19. Ilizarov GA. Clinical Application of the Tension-Stress Effect for Limb Lengthening. J Clin Orthop Relat Res. 1990; 250: 8-26

20. McCarthy JG, Schreiber J, Karp N, Thorne CH, Grayson BH. Lengthening the Human Mandible by Gradual Distraction. Plast Reconstr Surg. 1992;89: 1-8. 
21. Shehata EAA, Medra AMM. Modified bimaxillary distraction osteogenesis: A technique to correct facial asymmetry. Br J Oral Maxillofac Surg. 2007; 45: 471-7.

22. Stucki-McCormick SU. Reconstruction of the Mandibular Condyle Using Transport Distraction Osteogenesis. Journal of Craniofac Surg. 1997; 8: 36-41.

23. Jakhar SK, Agarwal M, Gupta DK, Tiwari AD. Preservation of condyle and disc in the surgical treatment of type III temporomandibular joint ankylosis: a long-term follow-up clinical study of 111 joints. Int J Oral Maxillofac Surg. 2013; 42: 746-51.

24. Sawhney CP. Bony Ankylosis of the Temporomandibular Joint: Follow-Up of 70 Patients Treated with Arthroplasty and Acrylic Spacer Interposition. Plastic and Reconstructive Surgery. 1986; 77: 29-38.

25. Cascone P, Agrillo A, Spuntarelli G, Arangio P, Iannetti G. Combined Surgical Therapy of Temporomandibular Joint Ankylosis and Secondary Deformity Using Intraoral Distraction. J Craniofac Surg. 2002;13: 401-9.

26. el-Sheikh MM. Temporomandibular joint ankylosis: the Egyptian experience. Ann R Coll Surg Engl. 1999; 81: 12-8.

27. Rajgopal A, Banerji PK, Batura V, Sural A. Temporomandibular ankylosis: A report of 15 cases. J Maxillofac Surg. 1983; 11: 37-41.

28. Temerek AT. Conservative gap arthroplasty in temporomandibular ankylosis not involving the sigmoid notch: a selected age group study. Br J Oral Maxillofac Surg. 2016; 54: e38-e43.

29. Topazian R. Comparison of gap and interposition arthroplasty in the treatment of temporomandibular joint ankylosis. J Oral Surg. 1966; 24: 405-9.
30. Al-Moraissi EA, El-Sharkawy TM, Mounair RM, ElGhareeb TI. A systematic review and meta-analysis of the clinical outcomes for various surgical modalities in the management of temporomandibular joint ankylosis. Int $\mathrm{J}$ Oral and Maxillofac Surg. 2015; 44 :470-82.

31. Resnick CM, Kaban LB, Troulis MJ. Minimally Invasive Orthognathic Surgery. Facial plast Surg. 2009; 25: 49-62.

32. Resnick CM. Temporomandibular Joint Reconstruction in the Growing Child. Oral Maxillofac Surg Clin North Am. 2018; 30: 109-21.

33. Mahran H. A comparative study between the intraoral and extraoral mandibular distractors in simultaneous maxillary correction of skeletal facial asymmetry in adults. PhD thesis. Maxillofacial and Plastic Surgery. Alexandria University; 2015.

34. Sadakah AA, Elgazzar RF, Abdelhady AI. Intraoral distraction osteogenesis for the correction of facial deformities following temporomandibular joint ankylosis: a modified technique. Int J Oral Maxillofac Surg. 2006; 35: 399-406.

35. Cai M, Lu X, Shen G, Wang X, Cheng AH-a. Customized Bifocal and Trifocal Transport Distraction Osteogenesis Device for Extensive Mandibular Reconstruction. J Craniofac Surg. 2011; 22: 562-5.

36. Xiao E, Zhang Y, An J, Li J, Yan Y. Long-term evaluation of the stability of reconstructed condyles by transport distraction osteogenesis. Int J Oral Maxillofac Surg. 2012; 41: 1490-4.

37. Verlinden CRA, van de Vijfeijken SECM, Tuinzing DB, Becking AG, Swennen GRJ. Complications of mandibular distraction osteogenesis for acquired deformities: a systematic review of the literature. Int J Oral Maxillofac Surg. 2015; 44: 956-64.

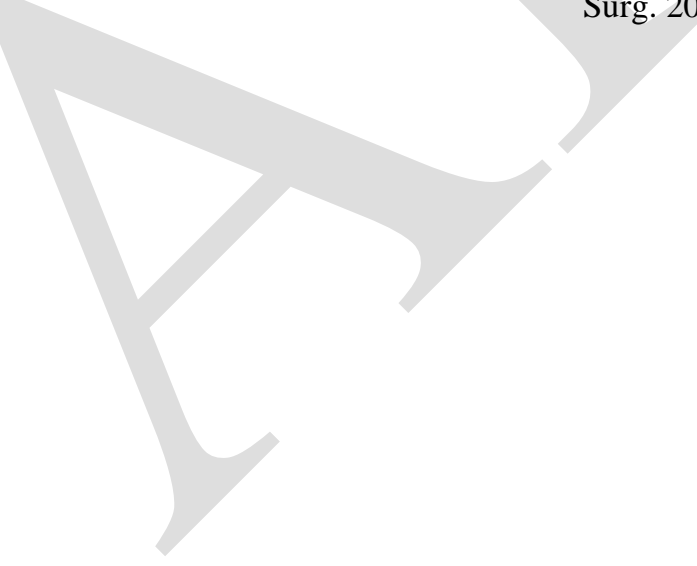

